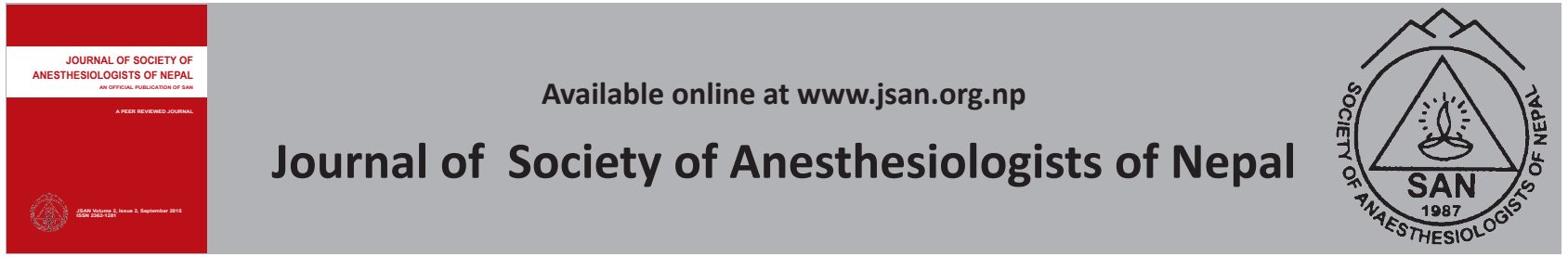

Original Article

\title{
Prospective randomized double blind comparison of analgesic efficacy of single shot epidural bupivacaine with or without dexamethasone in patients undergoing lower abdominal surgeries
}

\author{
Anuj Jung Rayamajhi , Balkrishna Bhattarai ${ }^{\epsilon}$, Birendra Prasad Shah $^{\epsilon}$ \\ ${ }^{\ddagger}$ Civil Service Hospital, Min Bhawan, Kathmandu, Nepal \\ ${ }^{€}$ BP Koirala Institute of Health Sciences, Dharan, Sunsari, Nepal
}

\author{
ARTICLE INFO \\ Article History \\ Received 13.07.2015 \\ Accepted 26.08.2015 \\ Published 10.09.2015 \\ (C) Authors retain copyright \\ and grant the journal right \\ of first publication with the \\ work simultaneously licensed \\ under a Creative Commons \\ Attribution License that allows \\ others to share the work with \\ an acknowledgement of the \\ workss authorship and initial \\ publication in this journal.
}

\begin{abstract}
Background: Epidural block with local anaesthetic with or without additives is being used for perioperative analgesia. Various additives have been used to enhance the effect of regional blocks including epidural blocks. This study aimed to investigate the effect of adding a single shot epidural dexamethasone to bupivacaine on postoperative analgesia and dose of rescue analgesics used.
\end{abstract}

Methods: A prospective, randomized, double blinded study was conducted in 90 adult patients undergoing lower abdominal surgery. The patients were randomized into two groups. Group 1 received $9 \mathrm{ml}$ of $0.5 \%$ bupivacaine plain with $1 \mathrm{ml}$ of normal saline. Group 2 received $9 \mathrm{ml}$ of $0.5 \%$ bupivacaine plain $9 \mathrm{ml}$ with $1 \mathrm{ml}$ of dexamethasone $(4 \mathrm{mg})$. After standard balanced anesthesia technique, patients were observed in postoperative period for pain and hemodynamic variables accordingly.

Results: Our study showed significantly longer duration of analgesia of 468 minutes (almost 8 hours) when dexamethasone was added to bupivacaine for single shot epidural injection compared to 271 minutes (approximately 4 and half hours) when bupivacaine alone was used $(p<0.001)$. Consumption of rescue analgesic, Tramadol, was significantly lower in dexamethasone group in 24 hours $(169.31 \pm 50.82 \mathrm{mg}$ in Group 1 and 114.77 $\pm 60.59 \mathrm{mg}$ in Group 2, p<0.001). No adverse events were noted.

Conclusion: Addition of dexamethasone to bupivacaine for single shot epidural block almost doubled the duration of analgesia. Single shot epidural block using bupivacaine with addition of dexamethasone provides effective post operative analgesia and significantly reduced the postoperative rescue analgesic requirement.

Keywords: bupivacaine; dexamethasone; epidural analgesia; postoperative pain.

How to cite this article: Rayamajhi AJ, Bhattarai B, Shah BP.Prospective randomized double blind comparison of analgesic efficacy of single shot epidural bupivacaine with or without dexamethasone in patients undergoing lower abdominal surgeries. JSAN 2015;2:46-51.

Corresponding author: Anuj Jung Rayamajhi, MD

Anesthesiologist, Civil Service Hospital,

Min Bhawan, Kathmandu, Nepal

Telephone: +9779851158004

Email: rajamajhianuj@hotmail.com 


\section{Introduction}

The regional nerve blocks serve dual purpose of anaesthesia for operation as well as analgesia for postoperative pain for considerable amount of time. Among the various regional blocks, epidural block with local anaesthetic with or without various additives is being used for intraoperative and post operative analgesia.

Epidural anesthesia with a local anaesthetic is known to provide better quality of postoperative analgesia in comparison with systemic opioids. It also lowers perioperative morbidity and mortality as compared to general anaesthesia alone. Various additives have been used to enhance the effect of regional blocks including epidural blocks. Addition of dexamethasone has been reported to result in quicker onset of action and prolonged duration of analgesia when used as additive in brachial plexus block. However, data on use of dexamethasone in epidural space for acute postoperative pain relief in lower abdominal surgeries is scarce. This prospective, randomized, double blind comparative study was designed to find out analgesic effect and duration of action of single shot epidural bupivacaine with or without dexamethasone in patients undergoing lower abdominal surgeries.

\section{Methods}

This was a prospective, randomized, double blind study conducted in patients of ASA physical status I and II of age group 16-70 years and undergoing routine elective lower abdominal surgery. Ethical approval obtained from the institutional ethical committee, written and informed consent was obtained from the patients. The patients were divided randomly into two equal groups using computers generated sequence maintained in sequentially numbered opaque envelopes and the study medication was given according to following distribution.

Group 1 received: - 9ml of $0.5 \%$ bupivacaine plain with 1 $\mathrm{ml}$ of $\mathrm{NS}$

Group 2 received: - $9 \mathrm{ml}$ of $0.5 \%$ bupivacaine plain $9 \mathrm{ml}$ with $1 \mathrm{ml}$ of dexamethasone $(4 \mathrm{mg})$

Allergy or any contraindication to study medication, ASA III and above, any contraindication to steroid- diabetes mellitus, hypertension, immunocompromised patient, morbidly obese patient and contraindication to epidural block- anticoagulant therapy, spine pathology and deformities were used as exclusion criteria. Medications used in the study involved $0.5 \%$ isobaric bupivacaine and dexamethasone.

\section{Anesthetic technique}

All recruited patients and their relatives were informed regarding the study, medication being used and expected co-operation from them for the study during preanesthetic check up in the ward, the evening before the surgery. Informed written consent was obtained from each patient for accepting participation in the study. During the visit, the patient was familiarized and explained about the use of visual analogue scale (VAS) for pain assessment ( 0 as " no pain at all" to 10 as "worst imaginable pain"). All the patients were premedicated with diazepam approximately $0.2 \mathrm{mg} / \mathrm{kg}$ given orally at night and morning before surgery.

On the day of operation, intravenous cannulation was established and patient monitor was attached for monitoring vital parameters (heart rate, NIBP, $\mathrm{SpO}_{2}$ ). The study medication was prepared by anesthesia assistant not involved in the study and the patients were also unaware of the drug administered. Epidural catheter was inserted in sitting or lateral position under all aseptic conditions. Skin was infiltrated with $3 \mathrm{ml}$ of $2 \%$ lignocaine prior to insertion of an $18 \mathrm{G}$ Tuohy needle at the L1-L2 intervertebral space. Catheter was fixed after administrating the test dose of $3 \mathrm{ml}$ of lignocaine with adrenaline 1:200000 (15 microgram adrenaline and $60 \mathrm{mg}$ lignocaine). Heart rate and BP after injection were monitored and noted. Then the patient was positioned for general anesthesia. Anesthesia was induced using propofol $(2 \mathrm{ml} / \mathrm{kg})$ and vecuronium was used for facilitation of endotracheal intubation and muscle relaxation, injection pethidine $(1 \mathrm{mg} / \mathrm{kg})$ was used for analgesia. Patients were mechanically ventilated with oxygen and isoflurane. Parameters monitored intraoperatively included non-invasive blood pressure (NIBP), heart rate, and pulse oximetry. The cumulative dose of pethidine and time of last pethidine supplement were recorded. All the patients received epidural block (bupivacaine with or without dexamethasone) 15 minutes prior to completion of surgery. The residual neuromuscular blockade was reversed using neostigmine and glycopyrrolate. VAS score for pain, level of consciousness, systolic $\mathrm{BP}, \mathrm{SpO}_{2}$ were recorded starting at 30 minutes postoperatively, and then at six hours intervals for 24 hours. After each VAS score patient was asked if he/she required additional analgesics regardless of his /her VAS score. Every patient was also instructed to request analgesics from the nurse whenever he/she required pain relief, and not to wait for their next scheduled pain assessment. Tramadol $50 \mathrm{mg}$ intravenously was given as rescue analgesic. No other analgesics or sedative was given for $24 \mathrm{hrs}$ after surgery. Time to first analgesia after surgery, hemodynamic variables (MAP, HR, $\mathrm{SpO}_{2}$ ) and occurrence of intra or post operative adverse events if any were noted.

\section{Assessment and management of pain}

The pain intensity was measured regularly at intervals mentioned above by using $10 \mathrm{~cm}$ Visual Analogue Scale (VAS). VAS ruler consisted of a $10 \mathrm{~cm}$ horizontal line with 'no pain' at one end and worst imaginable pain at other end.

Then the intensity of pain was assessed by asking the patient to grade the severity of pain they felt by pointing on the scale. The distance from patient's mark in $\mathrm{cm}$ from 
no pain (end 0) in whole number was taken as numerical index of the severity of pain.

If the severity of pain (VAS score) was more than four, then Tramadol $50 \mathrm{mg}$ was given slowly to the patient as a rescue analgesic and repeated if required. Time of administration of rescue analgesic and the total analgesic requirement in the post operative period for 24 hours were noted. Time of administration of first dose of rescue analgesic was considered as the time of termination of post operative analgesic effect of epidural block. The comparison of this duration of analgesia attained in the study groups was the primary objective of the study.

\section{Statistical analysis}

Sample size calculation was based upon the standard deviation of total Tramadol consumption in 24 hours postoperatively from patients who participated in a pilot study with a similar anesthetic and analgesic treatment. Assuming $\alpha=0.05$, and power of study $80 \%, 45$ patients per group were required to detect a difference of Tramadol consumption.

Data were entered into the master sheet in Microsoft Excel, Statistical Package for Social Science (SPSS version 15) was used for data analysis. Results were compared using independent t-test for continuous variables and chi square test for discrete variables. Level of significance was set at $\mathrm{p}<0.05$.

\section{Results}

All together 90 patients belonging to ASA physical status and II undergoing lower abdominal surgery under general anaesthesia were studied. The patient's age ranged from 16 to 65 years. The demographic parameters of the patients of both the groups were comparable (Table 1).

Table 1: Comparison of age, sex and weight

\begin{tabular}{|c|c|c|c|c|}
\hline \multirow{2}{*}{$\begin{array}{l}\text { Variable } \\
1(n=45)\end{array}$} & & \multicolumn{2}{|l|}{ Group } & \multirow{2}{*}{$\begin{array}{l}p- \\
\text { value }\end{array}$} \\
\hline & & $2(n=45)$ & & \\
\hline Age (years) & & $39.3 \pm 11.2$ & $37 \pm 10.6$ & 0.219 \\
\hline \multirow[t]{2}{*}{ Sex } & Female & $31(68.9 \%)$ & $28(62.2 \%)$ & 0.651 \\
\hline & Male & 13 (31.1\%) & $16(37.8 \%)$ & \\
\hline Weight (Kg) & & $54.7 \pm 11.4$ & 0.522 & \\
\hline $53.1 \pm 11.97$ & & & & \\
\hline
\end{tabular}

The values are in mean $\pm S D$, number (percentage)
Duration of analgesia following the administration of epidural block and analgesic consumption in 24 hours are given in figure 1.

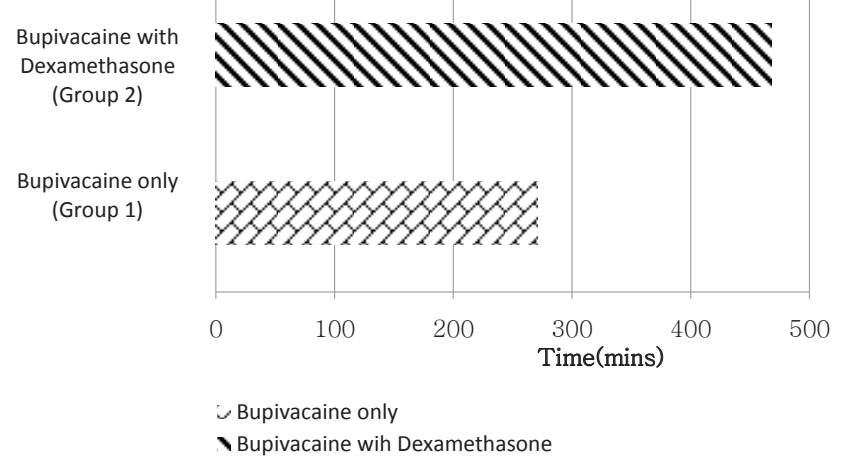

Figure 1: Comparison of duration of analgesia following epidural block

The mean duration $\pm S D$ of analgesia in group 2 $(478.40 \pm 147.5)$ minutes was significantly longer than that in group $1(271.13 \pm 121.7)$ minutes with $p$-value $<0.001$. Mean $( \pm S D)$ tramadol consumption in 24 hours was $169.31 \pm 50.82 \mathrm{mg}$ in Group 1 and $114.77 \pm 60.59 \mathrm{mg}$ in Group 2 . The difference was highly significant.

The pain VAS score and vital hemodynamic parameters documented at 0 minutes, 30 minutes, 360 minutes, 720 minutes, 1440 minutes after single shot epidural block administration. After 30 minutes of block administration (end of surgery) the mean pain VAS scores ( $\pm S D$ ) was comparable between the groups, $1.63( \pm 0.86)$ vs $1.27 \pm 0.81$ $(p>0.05)$.

At 360 minutes, mean VAS score \pm SD for pain in group 1 was more than that of group 2 and the difference was statistically highly significant $(3.09 \pm 0.67$ vs $2.34 \pm 1.11$ with $p$ value $<0.001$ ). At 720 and 1440 minutes mean VAS was again comparable (Figure2).

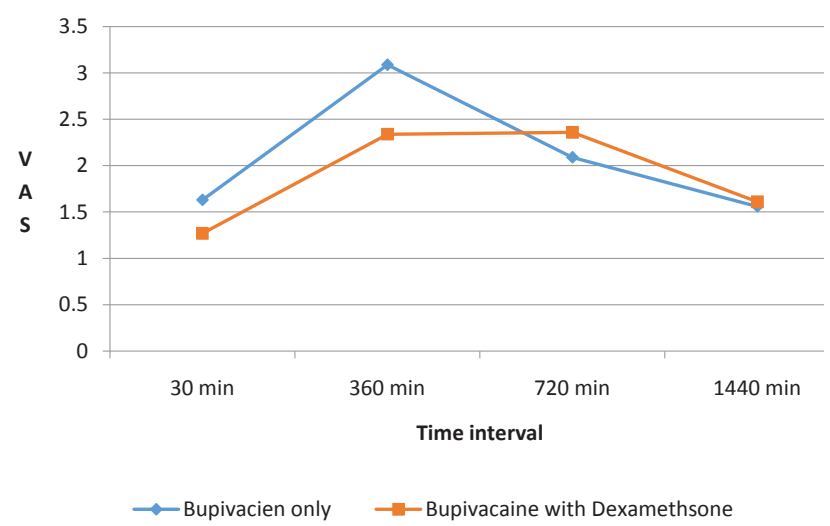

Figure 2: Comparison of VAS Score

In both the groups the lowest pulse rate was observed at 30 minutes following the block and highest at 360 minutes. While comparing the two groups at 720 minutes the pulse rate in group $1(81.20 \pm 7.48)$ was significantly less than that in group $2(85.34 \pm 9.01)$ ( $p$-value 0.022$)$. No significant 
difference was observed at 30 minutes, 360 minutes and 1440 minutes after the block (Figure 3).

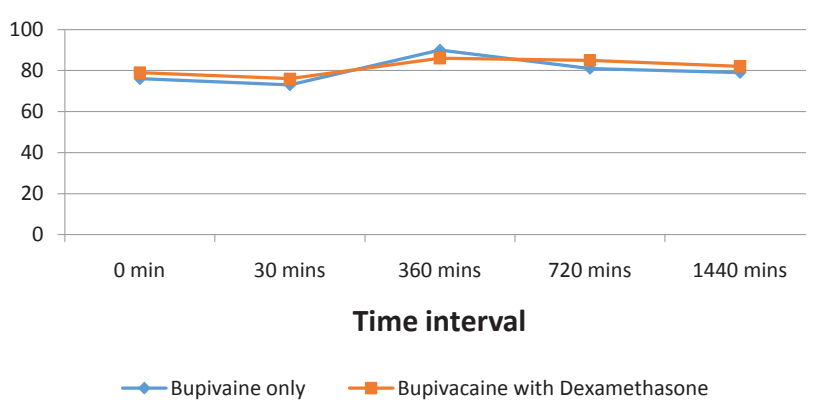

Figure 3: Comparison of Heart rate following block

In both the groups the lowest blood pressure was observed at 30 minutes following the block and highest at 360 minutes. While comparing the two groups at 360 minutes the blood pressure in group $2(120.56 \pm 12.06)$ was significantly less than that in group $1(125.90 \pm 9.54)$ $(p=0.024)$. No significant difference was observed at 30 minutes, 720 minutes and 1440 minutes after the block (Figure 4).

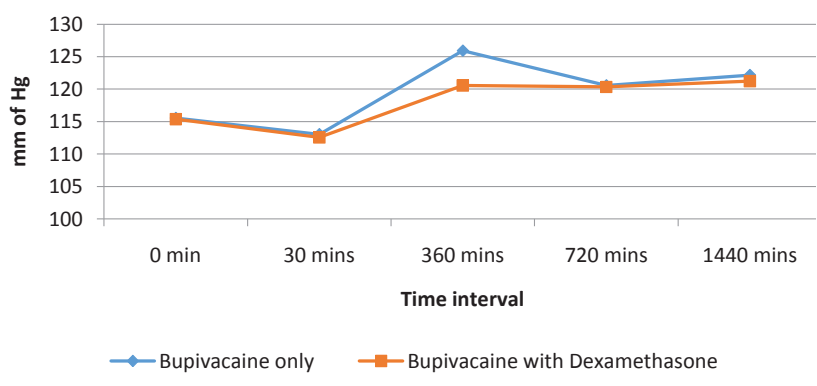

Figure 4: Comparison of systolic blood pressure following between two groups

No adverse events were noted.

\section{Discussion}

Due to its unpleasant nature and associated adverse consequences, postoperative pain has still remained a concern to practicing clinicians despite development and advances in various newer techniques and modalities for its management.

Epidural techniques are particularly effective at providing dynamic analgesia, allowing the patient to mobilize early and resume normal activities.

Epidural analgesia has been shown to have benefits over conventional intramuscular opioid analgesia and patient controlled analgesia using opioids." It provides excellent pain relief associated with minimal side effects and better patient satisfaction in comparison to other methods of analgesia. Epidural analgesia with local anaesthetics combined with opioids has been shown not only to provide better analgesia but also to improve post operative outcome.'
We chose bupivacaine as the local anaesthetic for both arms of our study as it has the best pharmacological profile for postoperative analgesia when used as single shot. Since dexamethasone, a steroid additive has been shown to hasten the onset and prolong the duration of regional blocks when used with local anaesthetic, we chose it as the study medication.

In order to give adequate time for onset and longest possible duration of analgesia we injected the study medication approximately 15 minutes prior to the end of surgery.

There was no significant difference between the two groups in respect to demographic characteristics including age, sex and weight of the subjects in the present study. Similarly no significant difference was observed between the groups in respect to type of surgical procedures, duration of anaesthesia and surgery, intra operative fluid administered, urine output and intraoperative analgesic requirement.

Since we injected our study medication through the epidural catheter at the end of the surgical procedure we could not assess the onset time of analgesia in our case and it was not the objective of the present study.

Our study showed significantly longer duration of analgesia of 468 minutes (almost 8 hours) when dexamethasone was added to bupivacaine for single shot epidural injection compared to 271 minutes (approximately 4 and half hours) when bupivacaine alone was used. In other words, addition of dexamethasone to bupivacaine for single shot epidural block almost doubled the duration of analgesia.

When dexamethasone $4-8 \mathrm{mg}$ was added as adjuvant to $2 \%$ lignocaine with adrenaline and $0.5 \%$ bupivacaine mixture for brachial plexus block in patients undergoing upper limb surgeries, Shrestha et $\mathrm{al}^{2}$ observed almost 4 times longer ( 12.75 hours Vs 3.11 hours) duration of analgesia as compared to the mixture without dexamethasone. Thus the findings in their study compares with our study quite well though they had much longer duration of analgesia with combination arm of their study. The difference can be considered quite expected and can be attributed to the difference in the study design, type of regional block and the local anaesthetic drugs and adjuvant used in the study.

Addition of small amount of dexamethasone to bupivacaine incorporated in microcapsules has been shown to prolong local analgesia through subcutaneous route in the study by Holte and colleague. Similar prolongation of the effect has been observed by Kopacz et al when dexamethasone added to bupivacaine was used for intercostal blockade in healthy volunteers.

To substantiate pain relief during post operative period we monitored VAS for pain, total analgesic requirement, pulse rate and blood pressure for up to 24 hours after the block. While comparing the pain VAS we found significantly higher VAS at 360 minutes in the group receiving bupivacaine 
alone as compared to the combination group mean $\pm S D$, (3.09 \pm 0.67 vs $2.43 \pm 1.11$, p-value $<0.001)$, median (IQR) [3.00(3.00-4.00) vs 3.00(1.25-3.00)]. This point of time corresponds closely with the time of termination of the duration of analgesia in that group. Significantly higher VAS for pain at 720 minutes in combination group similarly corresponds to the termination of effect of block and need of rescue analgesic in group 2. At this point of time, the group receiving bupivacaine alone expectedly had lower VAS owing to the effect of the rescue analgesic already received. Thereafter, the VAS for pain was lower in both the groups.

Post operative analgesic (Tramadol) requirement in our study has clearly demonstrated analgesic sparing effect of single shot dexamethasone added to bupivacaine for epidural analgesia. We observed almost 33\% reduction in analgesic requirement in the group receiving combination of dexamethasone and bupivacaine for epidural analgesia. Similar analgesic sparing effect of single shot dexamethasone has been observed by Thomas and colleagues when epidural administration of dexamethasone with or without bupivacaine was used in patients undergoing laparoscopic cholecystectomy.

Thomas and collegues ${ }^{16}$ also observed significantly lower VAS in the postoperative period up to 24 hours in the groups receiving epidural dexamethasone added to bupivacaine as compared to those receiving saline. Their study showed more than $50 \%$ reduction in post operative morphine consumption. Although there are major differences in the design and primary objective of their and our studies, both the studies have clearly demonstrated significant analgesic effect of epidural dexamethasone evidenced by reduction in VAS score and analgesic consumption.

Similar to the observation of VAS for pain, the maximum pulse rate was observed at 360 minutes after the block in both the groups. Significantly higher blood pressure (systolic) was observed in group receiving bupivacaine alone in comparison to bupivacaine and dexamethasone at $360 \mathrm{~min}(125 \pm 9.5$ vs $120 \pm 12 \mathrm{~mm}$ of $\mathrm{Hg}$, p-value 0.024$)$. This also corresponds closely with the time of termination of duration of analgesia in that group.

The limitation of this study is that we included surgical procedures producing different postoperative pain intensities in order to complete the study in the stipulated time period. This has contributed to some extent to heterogeneity of the observations despite our randomization. Comparison of epidural dexamethasone and opioids in combination with local anesthetic would be subject of future research.

\section{Conclusion}

Clinicians and researcher's interest in epidural analgesic techniques has never declined due to the quality of analgesia it offers not only in post operative pain but also in labour analgesia and chronic pain management.
Our study has shown that single shot epidural block using bupivacaine alone provides effective post operative analgesia for almost 4 hours and 51 minutes which can be further prolonged to around 7 hours by addition of dexamethasone while significantly reducing the postoperative analgesic requirement. Based on one finding we recommend the use of dexamethasone as additive to local anaesthetics for single shot epidural analgesia wherever appropriate.

\section{Funding: Nil}

Acknowledgments: Nil

\section{Conflict of interest: None}

\section{References}

1. Rodgers A, Walker N, Schug S, McKee A, Kehlet H, Van Zundert $A$, et al. Reduction of postoperative mortality and morbidity with epidural or spinal anaesthesia: results from overview of randomised trials. Bmj 2000;321:1493.

2. Shrestha BR, Maharjan SK and Tabedar S. Supraclavicular brachial plexus block with and without dexamethsone -A comparative study. KUMJ 2003;1:158-60.

3. $\mathrm{Wu} \mathrm{CL}$, Raja SN. Treatment of acute postoperative pain. Lancet 2011;377:2215-25.

4. Weissman C. The metabolic response to stress: an overview and update. Anesthesiology 1990;73:308-27.

5. Nimmo SM. Benefit and outcome after epidural analgesia. Contin Educ Anaesth Crit Care Pain 2004;4:44-7.

6. Negre I, Gueneron JP, Jamali SJ, Monin S, Ecoffey C. Preoperative analgesia with epidural morphine. Anesth Analg 1994; 79:298-302.

7. Benzon HT, Wong HY, Belavic AM Jr, Goodman I, Mitchell D, Lefheit $\mathrm{T}$, et al. A randomised double blind comparison of epidural fentanyl infusion versus patient controlled analgesia with morphine for post thoracotomy pain. Anesth Analg 1992; 76:31622.

8. Hjortso NC, Neumann P, Frosig F, Andersen T, Lindhard A, Rogon $E$, et al. A controlled study of the effect of epidural analgesia with local anaesthetics and morphine on morbidity after abdominal surgery. Acta Anaesthes Scand 1985;29:705-16.

9. Jensen $\mathrm{K}$, Kehlet $\mathrm{H}$, Lund $\mathrm{CM}$. Post-operative recovery profile after laparoscopic cholecystectomy, a prospective, observational study of a multimodal anesthetic regime. Acta Anaesthesiology Scand 2007; 51:464-71.

10. Thomas S, Beevi S. Epidural Dexamethasone reduces postoperative pain and analgesic requirement. Can J Anesth 2006;53:889-905.

11. Liu SS, Carpenter RL, Mackey DC, Thirlby RC, Rupp SM, Shine TS, et al. Effects of perioperative analgesic technique on rate of recovery after colon surgery. Anesthesiology 1995;83:757-65.

12. de Leon-Casasola OA, Parker BM, Lema MJ, Groth RI, Orsini Fuentes J. Epidural analgesia versus patient controlled analgesia. Differences in the postoperative course of cancer patients. Reg Anesth 1994;19:307-15. 
13. Movafegh A, Razazian M, Hajimaohamadi F, Meysamie A.

Dexamethasone added to lidocaine prolongs axillary brachial plexus blockade. Anesthesia Analgesia 2006;102:263-7.

14. Holte K, Werner MU, Lacouture PG, Kehlet H.. Dexamethasone Prolongs Local Analgesia after Subcutaneous Infiltration of Bupivacaine Microcapsules in Human Volunteers. Anaesthesiology 2002;96:1331-5.

15. Kopacz DJ, Lacouture PG, Wu D, Nandy P, Swanton R, Landau C. The dose response and effects of dexamethasone on bupivacaine microcapsules for intercostal blockade (T9 to T11) in healthy volunteers. Anesth Analg 2003;96:576-82.

16. Thomas S, Beevi S. Epidural Dexamethasone reduces postoperative pain and analgesic requirement. Can J Anesth 2006;53:889-905. 